Research Paper:

\title{
Investigating the Mediating Role of Perceived Organi- zational Support in the Relationship Between Sense of Coherence, Professional Ethics, and Job Performance of Nurses
}

\author{
Narges Rasouli ${ }^{1}$ (i), Alireza Heidari ${ }^{1^{*}}$ (D) Farah Naderi $^{1}$ Fatemeh Sadat Marashian $^{1}$
}

1. Department of Psychology, Ahvaz Branch, Islamic Azad University, Ahvaz, Iran.

\begin{tabular}{|l|l|}
\hline $\begin{array}{l}\text { use your device to scan } \\
\text { and read the article online }\end{array}$ & $\begin{array}{l}\text { Cttation: Rasouli, N., et al., 2020. Investigating the Mediating Role of Perceived Organizational Support in the Relationship } \\
\text { between Sense of Coherence, Professional Ethics, and Job Performance of Nurses. Journal of Client-Centered Nursing Care, } \\
\text { 6(1), pp. 31-42. https://doi.org/10.32598/JCCNC.6.1.324.1 }\end{array}$ \\
dol https://doi.org/10.32598/JCCNC.6.1.324.1
\end{tabular}

\section{(c) (1) (s)}

Article info:

Received: 02 Aug 2019

Accepted: 05 Jan 2020

Published: 01 Feb 2020
Keywords:

Job performance,

Sense of coherence,

Professional ethics,

Perceived organizational

support, Nurses

\begin{abstract}
A B S T RA C T
Background: Job performance is one of the basic concepts in organizations, based on which, the responsibilities and success of each individual in the organization are realized. The main objective of the current study was to investigate the mediating role of perceived organizational support in the relationship between Sense of Coherence (SOC), professional ethics, and the job performance of nurses in Ahvaz City, Iran.
\end{abstract}

Methods: This study was model-based testing research. The statistical population included all the nurses working in Golestan Hospital of Ahvaz City, Iran, in 2019. Of them, 252 nurses were selected as the study sample using the voluntary sampling method. The research instruments included Paterson's job performance questionnaire, the SOC scale, professional ethics questionnaire, and survey of perceived organizational support. Model fit was evaluated using path analysis with AMOS software.

Results: The results showed that all direct paths, except for the path from the SOC to job performance were significant $(\mathrm{P}<0.01)$. Moreover, the indirect paths through perceived organizational support to job performance were also significant $(\mathrm{P}<0.01)$.

Conclusion: According to the study results, the proposed model had a good fit, and it can be considered as an important step towards identifying the factors affecting the job performance of nurses.

\footnotetext{
* Corresponding Author:

Alireza Heidari, PhD.

Address: Department of Psychology, Ahvaz Branch, Islamic Azad University, Ahvaz, Iran.

Tel: +98 (613) 3329200

E-mail: heidaria945@gmail.com
} 


\section{Highlights}

- Nurses' sense of cohesion has a positive effect on their perceived organizational support.

- Professional ethics has a positive effect on job performance and the perceived organizational support of nurses.

- Nurses' perceived organizational support has a positive effect on their job performance.

\section{Plain Language Summary}

The nurses' shifting work has negative effects on family and social aspects of their life. Affecting the perceived organizational support, the sense of cohesion and professional ethics can involve the nurses' job performance. In general, this study found that the sense of cohesion has a positive effect on perceived organizational support. Also, professional ethics has a positive effect on job performance and perceived organizational support. Finally, perceived organizational support has a positive effect on job performance.

\section{Introduction}

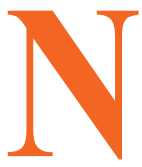

urses are among the most important occupational groups and the main body of healthcare organizations in terms of numbers. It is worth mentioning that nursing is considered a stressful job. Due to shift rotations, a nurse usually spends several hours a day in the hospital on weekdays (de Souza, Pessoa Júnior \& de Miranda 2017). Literature shows that the shift work nature of nursing has had several negative impacts on their family and social life. Moreover, this condition may lead to the breakdown of common social activities with the spouse, endangering the mental health of nurses (Guo et al., 2016). Work shifts may result in social isolation, increased depression, and reduced mutual marital interactions (Orgambidez-Ramos et al., 2017), which can end in reduced quality of job commitment and job performance of nurses (Farahaninia et al., 2019; Tims, Bakker \& Derks 2013).

Job performance is considered as one of the most fundamental concepts in organizations, based on which, the responsibilities and success of each individual in the organization are formed (Masa'deh, Obeidat \& Tarhini 2016). Lazaroiu (2015) believes that job performance is a product of human behaviors in such a way that motivations and needs of individuals, affect their performance and ultimately, economic growth and development. Job performance is a multidimensional construct, showing the performance of the employees in their jobs, the level of their initiative and problem-solving capabilities, and the strategies for using available resources and time and energy for performing job responsibilities (Viswesvaran \& Ones 2017).
Sense Of Coherence (SOC) is one of the effective factors on the job performance of nurses. SOC refers to possessing sufficient resources to withstand stressful situations, including workplace stresses (Ando \& Kawano 2018), and involves three components of understandability, manageability, and meaningfulness (Winger, Adams \& Mosher 2016). If people possess such a personality characteristic, they will see internal and external stimuli in everyday life as predictable; they also believe that sufficient resources are available for facing the demands of these stimuli (Vainio \& Daukantaite 2016). Various studies have confirmed the relationship between SOC and job performance among employees and nurses (Ehteshamzadeh, Sabri Nazarzadeh \& Memarbashi Aval 2014; Memarbashi, Sabri Nazarzadeh \& Abdolkhodaei 2012; Debska, Pasek \& Wilczek-Rużyczka 2017).

Professional ethics constitute another factor that seems to affect the job performance of nurses. Many successful workplaces have realized that an ethics-based culture must be present in the organization (Banks 2015). Professional ethics, with the meaning of respecting the rights of individuals in a profession, has a much broader concept than the professional regulations and rules. Professional ethics are more wide-ranging than the law since many ethical considerations have not been ratified in the form of laws (Kangasniemi, Pakkanen \& Korhonen 2015). Various studies have confirmed the relationship between professional ethics and job performance among employees and nurses (Sagheb Esmaeelpour et al., 2019; Taheri Attar, Pourahmadi \& Herati 2019; Shaghozaei Marziyeh \& Nastezaei 2018; Özden et al., 2019; Skela-Savic \& Kiger 2015). 


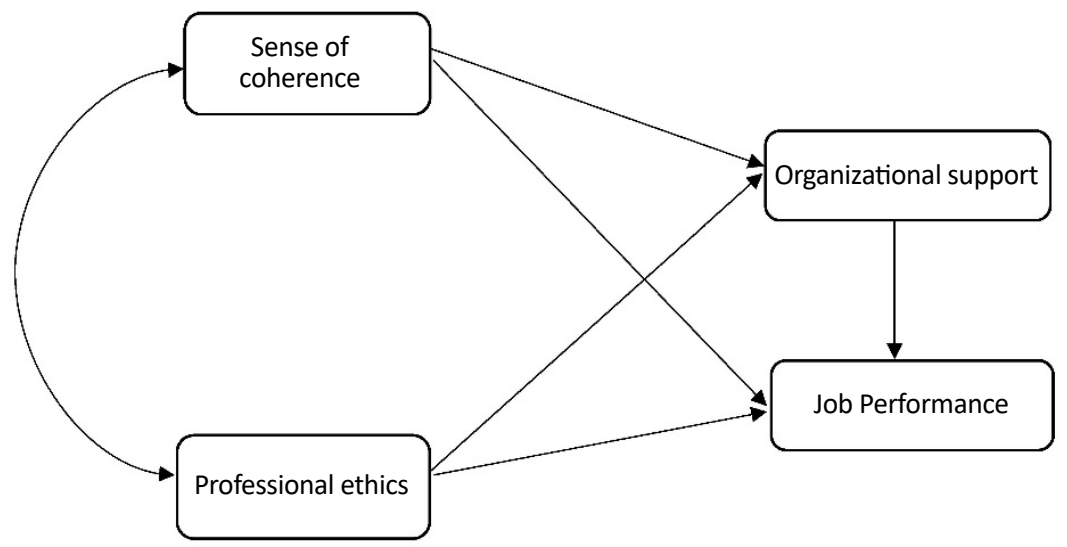

Figure 1. The proposed model of the research

Client- Centered Nursing Care

Through affecting the perceived organizational support, both SOC and professional ethics can be effective for the job performance of nurses. The theoretical foundations of organizational support are rooted in the social exchange theory. According to this theory, if someone helps or does a favor for someone else, the other party will be obligated to reciprocate the favor (Lamm,TostiKharas \& King 2015). In other words, perceived organizational support refers to the perceptions of the employees about how much the organization values their contributions and how much it cares about their wellbeing (Vasegh Rahimparvar et al., 2018; Caesens et al., 2016). The theory of organizational support posits that employees create a general view about the support they receive from the organization, and in turn, they pay attention to the goals and objectives of the organization as well as the realization of these goals and objectives (Zhong, Wayne \& Liden 2016).

Perceived organizational support is associated with a large number of organizational variables, including the relationship between the employees and their supervisors, and providing rewards. Organizational support creates a positive and safe environment and leads to the loyalty of the individuals towards the organization (DeConinck $\&$ Deconinck 2017). The higher the perceived organizational support by the employees, the better their performance, and this increases their efficiency and results in their willingness to stay in the organization. Perceived organizational support reduces occupational pressure and intention to leave the organization (Kim, Eisenberger \& Baik 2016). The supporting behaviors of the leaders and the organizational atmosphere can create the perceived supports (Fagbenro, 2019; Zheng \& Wu 2018). In similar studies, it has been shown that perceived organizational support was related to job performance. In general, job performance is not only related to people's mental health but also their productivity. Therefore, identifying the effective mechanisms for coping with mental pressures can help promote mental health and boost the efficiency and productivity of human resources (Ghanbari, Soltaninejad \& Badafara 2018; Bai 2017; Nasiri Valikbani 2014).

Considering the profound role of nurses in maintaining the mental-social balance of the community, as well as various personal and occupational problems and issues facing the nurses, there is an urgent need for planning to resolve their problems. On the other hand, according to the research background, the perceived organizational support was used as a predictor variable for job performance. Also, in some cases, perceived organizational support was used as a criterion variable for the sense of coherence and professional ethics. Therefore, in the present study, we used perceived organizational support as a mediating variable to examine how this variable affects job performance in nurses by influencing the SOC and professional ethics.

Based on the issues outlined above, the main objective of the current study is to investigate the mediating role of perceived organizational support in the relationship between SOC and professional ethics and the job performance of nurses in Ahvaz City. Figure 1 shows the proposed model of research design.

\section{Materials and Methods}

To attain the objectives of the study, the correlation method was utilized, while path analysis by modelbased testing was used for examining the hypotheses. The study population included all the nurses working in 
Golestan Hospital of Ahvaz City, Iran, in 2019. Using the voluntary sampling method, 290 questionnaires measuring the variables of the study were given to the selected participants to answer. The inclusion criteria were work experience over 6 months, age range between 2148 years, having no mental disorders, and written consent to participate in the research. The exclusion criteria included failure to completely answer all the questions and a lack of willingness to continue participating in the study. Ultimately, 252 questionnaires were filled out by the subjects and analyzed.

\section{Research instruments}

\section{Job Performance Questionnaire}

The job performance questionnaire was developed by Paterson (1970). It includes 15 items used to measure the job performance of employees. The scoring for the questionnaire is based on a 4-point Likert-type scale where scores of $0,1,2$, and 3 are given to options "rarely", "sometimes", "often", and "always", respectively. The scores for each participant can range from 0 to 45. A higher score indicates better job performance. The content validity of the questionnaire was confirmed by Shaghozaei Marziyeh \& Nastezaei (2018), while they reported reliability of 0.82 based on the Cronbach $\alpha$ coefficient for this tool. In the current study, to evaluate the internal consistency of the job performance questionnaire, a Cronbach $\alpha$ coefficient of 0.84 was obtained for all questions.

\section{Sense of Coherence Scale}

The Sense of Coherence (SOC) scale was revised and utilized by Flensborg-Madsen, Ventegodt \& Merrick (2006) based on the original version of Antonovsky (1987). This scale includes 35 questions with three or five options. The options for questions 1 to 24 are scored based on a 3-point Likert scale as follows: the option "yes" gets a score of 3, the option "I don't know" gets a score of 2, and the option "no" gets a score of 1. Moreover, questions 25 to 35 are rated on a 5-point Likert scale, and scored as follows: if the participant chooses either of the two first options ("highly satisfied" and "satisfied"), s/he gets the highest score, i.e. 3. If the participant chooses the option of "sometimes satisfied and sometimes not", s/he will get a score of 2 . Finally, if the participant chooses either of the last two options ("unsatisfied" or "highly unsatisfied"), s/he will get a score of 1 , which is the lowest possible score. This scale includes three subscales, including understandability, manageability, and meaningfulness. However, in the Persian version of the scale, the subscales are not delineated. The total score for this scale ranges from 35 to 105 . A higher score indicates a higher level of SOC in the individual. Flensborg-Madsen, Ventegodt \& Merrick (2006) confirmed the content and construct validities of the scale. To assess the reliability of the scale, he reports the Cronbach $\alpha$ coefficients of 0.87 and 0.86 in two studies, respectively. Moradi, Ghodrati Mirkohi \& Hayati (2019) reported that the reliability of the questionnaire was 0.84 using the Cronbach $\alpha$. In the current study, a Cronbach $\alpha$ coefficient of 0.82 was obtained for all items of the scale after evaluating its internal consistency.

\section{Professional Ethics Questionnaire}

The Professional ethics questionnaire was developed by Cadozir (2002) and includes 17 closed questions, measuring the dimensions and characteristics of professional ethics based on eight components of accountability, honesty, justice and fairness, loyalty, striving for superiority and competitiveness, respect, sympathy for others, and respect for social values and norms. To score the items in the questionnaire, a 5-point Likert scale is used as "very much" (5), "much" (4), "medium" (3), "low" (2), and "very low" (1). The questions on professional ethics include questions 1 to 17: questions 1 and 2 are related to accountability; questions 3 and 4 to honesty; questions 5 to 7 to justice and fairness; questions 8 and 9 to loyalty; questions 10 and 11 to striving for superiority and competitiveness; questions 12 and 13 to respect; questions 14 and 15 to sympathy for others; and questions 16 and 17 to respecting social norms and values. The total score for this questionnaire ranges from 17 to 85. A higher score indicates higher professional ethics. In a study, Akbari, Ghasemi Shams \& Pour Mohammasali Chaijani (2018) reported a Cronbach $\alpha$ coefficient of 0.89 for the reliability of this scale. In the current study, the Cronbach $\alpha$ coefficient for the entire questionnaire was obtained as 0.86 .

\section{Survey of perceived organizational support}

The survey of perceived organizational support was developed by Eisenberger et al. (2001). This survey includes 8 questions and evaluates perceived organizational support. To prevent bias in the answers, some questions are scored as negative, and some as positive. A 5-point Likert type scale is used for scoring, from strongly disagree (1) to strongly agree (5) for the positive questions and strongly agree (1) to strongly disagree (5) for the negative questions. The total score for this questionnaire ranges from 8 to 40 . A higher score indicates higher perceived organizational support. The reliability 
of this scale, using the Cronbach alpha coefficient, was reported as 0.86 by Eisenberger et al. (2001). This scale was translated into Persian by Zaki (2006), who reported reliability of 0.89 using the Cronbach alpha coefficient for 100 participants. Moreover, the validity of this scale was confirmed by Oreizi Samani, Dibaji \& Sadeghi (2012) using exploratory and confirmatory factor analyses, which indicated the convergent and divergent validity for the scale. Furthermore, the one-dimensionality of the scale was also confirmed by confirmatory factor analysis. In the current study, the Cronbach alpha coefficient for the entire questionnaire was obtained as 0.82 .

Analysis of the data involved both descriptive and inferential statistics including mean, standard deviation, the Pearson correlation, and path analysis. Data analysis was done using SPSS version 24. Model fit was evaluated using path analysis with AMOS software.

\section{Results}

The participants included 252 nurses (Mean \pm SD age: $38.46 \pm 7.81$ years). About $57.53 \%$ of the nurses participating in the study were female, and $42.47 \%$ were male. Concerning educational level, $85.31 \%$ had a bachelor's degree, and $14.68 \%$ a master's degree.

Descriptive statistics including mean, standard deviation, and the list of variables of the study are presented in Table 1. Moreover, the correlation matrix for the research variables is presented in Table 2 .
According to Table 2, the results of the Pearson correlation show a positive and significant relationship between all study variables at $\mathrm{P}<0.01$ level. The preliminary model obtained for explaining job performance based on SOC, professional ethics, and perceived organizational support is shown in Figure 2.

The root mean square error of approximation index (RM$\mathrm{SEA}=0.407$ ) showed that the preliminary model required correction (Table 3). To correct the model, the insignificant relationship between SOC and job performance was eliminated from the model. The final model is depicted in Figure 3. The results confirm the good fit of the model.

The findings in Table 4 showed that the relationship between SOC and job performance was not statistically significant $(\beta=0.080, \mathrm{P}=0.170)$. There was a positive and significant relationship between SOC and perceived organizational support among nurses $(\beta=0.385, \mathrm{P}<0.01)$. There was also a positive and significant relationship between professional ethics and job performance of the nurses $(\beta=0.294, \mathrm{P}<0.01)$. There was a positive and significant relationship between professional ethics and perceived organizational support among the nurses $(\beta=0.421$, $\mathrm{P}<0.01)$. Finally, there was a direct and significant relationship between the perceived organizational support and job performance of nurses in Ahvaz City $(\beta=0.273$, $\mathrm{P}<0.01)$. To determine the significance of mediatorybased relations, the bootstrap method was utilized.

Table 1. The mean and standard deviation of research variables

\begin{tabular}{llll}
\hline \multicolumn{1}{c}{ Variables } & Mean \pm SD & No. \\
\hline \multicolumn{2}{c}{ Job performance } & $25.33 \pm 12.68$ \\
Sense of coherence & $76.00 \pm 20.45$ & 252 \\
Professional ethics & $59.33 \pm 16.64$ & \\
Perceived organizational support & $48.85 \pm 26.16$ & \\
\hline
\end{tabular}

Client- Centered Nursing Care

Table 2. The Pearson correlation coefficient between variables

\begin{tabular}{ccccc}
\hline Variables & $\mathbf{1}$ & $\mathbf{2}$ & $\mathbf{3}$ & $\mathbf{4}$ \\
\hline 1. Job performance & 1 & & & \\
2. Sense of coherence & $0.333^{*}$ & 1 & & \\
3. Professional ethics & $0.531^{*}$ & $0.383^{*}$ & 1 & 1 \\
\hline${ }^{*} \mathrm{P}<0.01$ & $0.479^{*}$ & $0.455^{*}$ & $0.533^{*}$ & Client- Centered Nursing Care
\end{tabular}




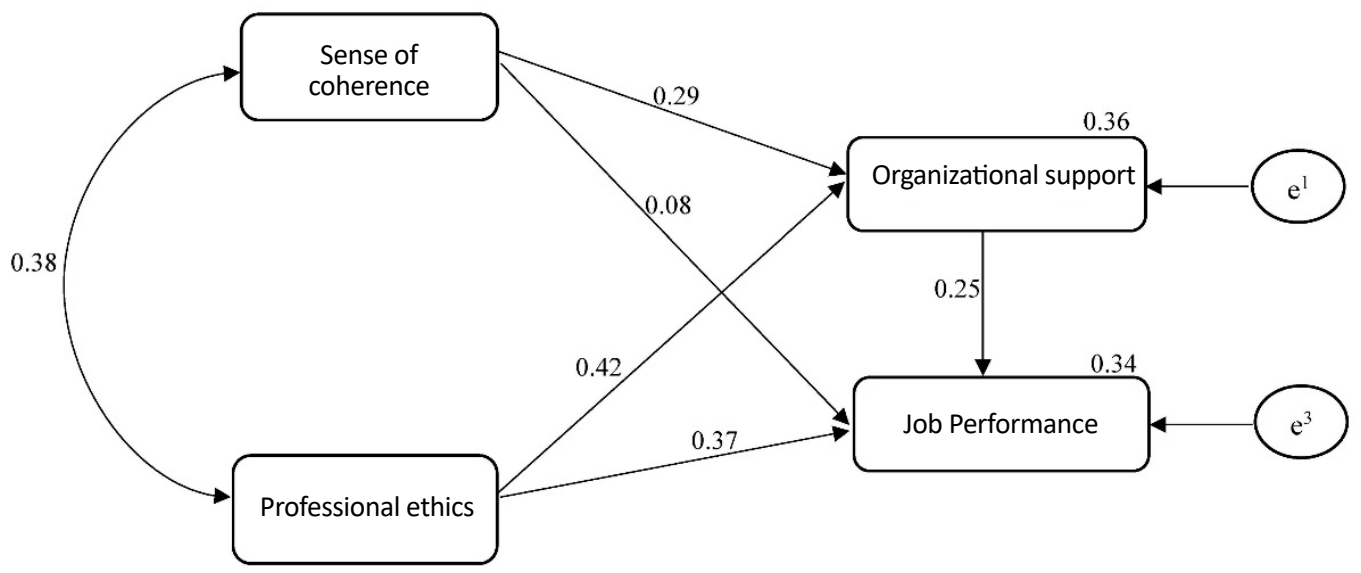

Figure 2. Initial proposed model

Client- Centered Nursing Care

Table 3. Initial and final model fit indicators

\begin{tabular}{ccc}
\hline Fit Indicators & Initial Model & Final Model \\
\hline$\chi^{2}$ & 0.000 & 1.870 \\
\hline $\mathrm{df}$ & 0 & 1 \\
\hline$\left(\chi^{2} / \mathrm{df}\right)$ & - & 1.870 \\
$\mathrm{p}$ & - & 0.170 \\
\hline $\mathrm{TFI}$ & - & 0.970 \\
$\mathrm{GFI}$ & 1.000 & 0.990 \\
\hline $\mathrm{NFI}$ & 1.000 & 0.990 \\
\hline $\mathrm{CFI}$ & 1.000 & 0.990 \\
\hline RMSEA & 0.407 & 0.059 \\
\hline
\end{tabular}

Client- Centered Nursing Care

TFI: Tucker Lewis Index (ideal value $>0.9$ ); GFI: Goodness-of-Fit Index (ideal value $>0.9$ ); NFI: Normalized Fit Index (ideal value $>0.9$ ); CFI: Comparative Fit Index (ideal value >0.9); RMSEA: Root Mean Square Error of Approximation (ideal value $\leq 0.05$ close fit)

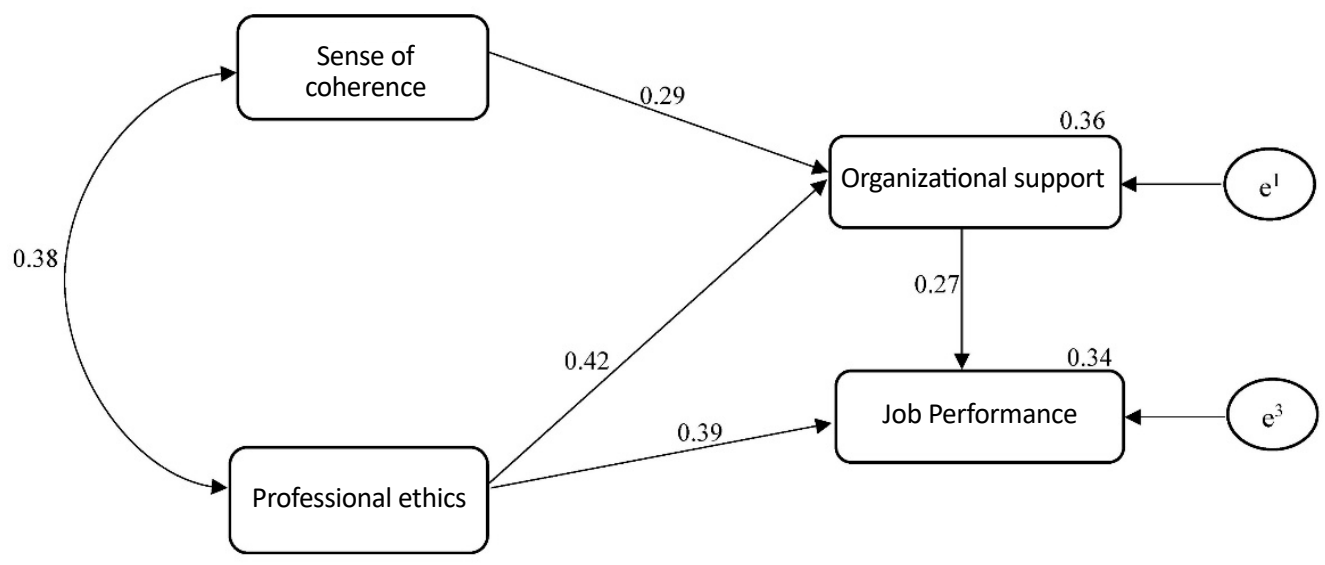

Figure 3. Final modified model

Client- Centered Nursing Care 
Table 4. Path coefficients of direct effects between research variables in the initial and final model

\begin{tabular}{|cccccccc}
\hline & \multicolumn{3}{c}{ Initial Model } & & \multicolumn{3}{c}{ Final Model } \\
\cline { 2 - 7 } & Path & Path Type & $\boldsymbol{\beta}$ & $\mathbf{P}$ & Path Type & $\boldsymbol{\beta}$ & $\mathbf{P}$ \\
\hline Sense of coherence to job performance & Direct & 0.080 & 0.170 & Direct & - & - \\
\hline Professional ethics to job performance & Direct & 0.370 & 0.001 & Direct & 0.385 & 0.001 \\
\hline Sense of coherence to perceived organizational support & Direct & 0.294 & 0.001 & Direct & 0.294 & 0.001 \\
\hline Professional ethics to perceived organizational support & Direct & 0.421 & 0.001 & Direct & 0.421 & 0.001 \\
\hline Perceived organizational support to job performance & Direct & 0.245 & 0.004 & Direct & 0.273 & 0.001 \\
\hline
\end{tabular}

Client- Centered Nursing Care

Table 5. Results of the bootstrap method for investigating indirect and intermediary paths

\begin{tabular}{ccccccc}
\hline \multirow{2}{*}{ Predictor Variable } & Mediator Variable & Criterion Variable & \multicolumn{2}{c}{ Initial Model } & \multicolumn{2}{c}{ Final Model } \\
\cline { 4 - 7 } & & & Bootstrap & P & Bootstrap & P \\
\hline Sense of coherence & Perceived organizational support & Job performance & 0.045 & 0.009 & 0.050 & 0.009 \\
Professional ethics & Perceived organizational support & Job performance & 0.079 & 0.010 & 0.088 & 0.011 \\
\hline
\end{tabular}

Client- Centered Nursing Care

The indirect path from SOC to job performance through the mediating role of perceived organizational support was significant $(\beta=0.050, \mathrm{P}<0.01)$. Moreover, the indirect path from professional ethics to job performance through the mediating role of perceived organizational support was also significant $(\beta=0.088, \mathrm{P}<0.05)$ (Table 5).

\section{Discussion}

The present study aimed to investigate the mediating role of perceived organizational support in the relationship between Sense Of Coherence (SOC) and professional ethics, and the job performance of nurses in Ahvaz City. The results of the current study showed no direct relationship between SOC and job performance. This finding is in contrast to the findings of studies carried out by Ehteshamzadeh, Sabri Nazarzadeh \& Memarbashi Aval (2014), Memarbashi, Sabri Nazarzadeh \& Abdolkhodaei (2012), and Debska, Pasek \& Wilczek-Rużyczka (2017). In those studies, the relationship between SOC and job performance was evaluated using correlation coefficient and regression tests, which showed a significant relationship. While in the current study, the hypotheses were tested using path analysis. It is worth mentioning that in the current study, the relationship between SOC and job performance was significant based on the Pearson test. However, in the proposed model, due to the presence of the mediatory variable, all the contributions and effects from the variable of SOC on job performance have been explained through the mediatory variable, i.e. through an indirect relation. In other words, in this model, the variable of SOC also had an indirect impact on job performance. Therefore, this finding is somewhat in line with the results of previous studies. Specifically, SOC was affecting job performance, albeit in an indirect manner, which means that the presence of SOC in the nurses had an important impact on their perceived organizational support, which in turn affected their job performance. On the other hand, it seems that in the relationship between SOC and job performance of nurses, more mediatory variables may be involved. These may include the individual specifications of participants that can also be effective in perceiving organizational support, affecting job performance, and finally, an increase in job performance. Therefore, it is possible that if we study the effects of the variables of the study more closely, we may find mediatory variables that challenge the direct impact of SOC on job performance.

There was a positive relationship between SOC and perceived organizational support. This finding is consistent with the results of Qorbanpoor Lafmejani, Yaghouti \& Rezaei (2019). To explain this finding, it can be said that SOC is felt when the people believe that the life events they face are understandable and can be resolved, i.e. there are resources for coping with these events. One of the required resources to deal with such problems is the support received from family members, 
friends, colleagues, and more importantly, from the boss, the supervisors, or the superiors, that could have various aspects Lamm, Tosti-Kharas \& King (2015). Hence, SOC increases the perception of organizational support. In general, SOC affects the nature of interpersonal relationships when facing uncomfortable situations and problems. Moreover, utilizing transcendental awareness, creation of personal meaning, critical thinking, and the development and expansion of the state of consciousness could affect job performance (Winger, Adams \& Mosher 2016). Besides, SOC provides a framework for identifying and organizing skills and capabilities as well as valuable insights, including a set of required beliefs and values. Also, these characteristics can affect the perceived organizational support (Qorbanpoor Lafmejani, Yaghouti \& Rezaei 2019).

The results showed a positive and significant relationship between professional ethics and job performance. This finding is consistent with the research results of Sagheb Esmaeelpour et al. (2019), Taheri Attar, Pourahmadi \& Herati (2019), Shaghozaei Marziyeh \& Nastezaei (2018), Özden et al. (2019), and Skela-Savic and Kiger (2015). To explain this finding, it can be said that professional ethics play an important role in job performance. Accordingly, religious beliefs and rituals help individuals manage their problems and tensions in cognitive, emotional, and physiological dimensions (Ekramifar et al., 2018). Moreover, these beliefs can help them to accept responsibility for their thoughts and actions when they confront conflicts and challenges and try to change them (Taheri Attar, Pourahmadi \& Herati 2019). When employees show perseverance and seriousness in the workplace, respect healthy and human-based relations in the workplace, and have a collective spirit and participatory disposition, improved job performance can be expected (Ekramifar et al., 2018).

There was a positive relationship between professional ethics and perceived organizational support. In other words, by promoting the professional ethics of the nurses, their perceived organizational support increases. To explain this finding, it can be said that organizations are always looking to find strategies for increasing the work efficiency of their employees (Özden et al., 2019). Moreover, organizations require employees with high levels of professional ethics who are accountable for the responsibilities and tasks delegated to them (Skela-Savic \& Kiger 2015). Ethics leads the employees to receive organizational support from their superiors, and it increases their popularity in the organization since these people can contribute to the organization's dynamics more than any other type of employee (Chye Koh \& Boo, 2004).
There was a positive relationship between perceived organizational support and job performance. By increasing perceived organizational support among nurses, their job performance improves. This finding is consistent with the research results of (Ghanbari, Soltaninejad \& Badafara 2018; Bai 2017), and Nasiri Valikbani (2014). To explain this finding, it can be said that a high level of perceived organizational support has led to nurses' commitment to the organization. So they have reciprocated these benefits and rewards with improved job performance. Since employees are the most important capital for any institution, the organization must provide comprehensive support for them (Bai 2017). When employees believe that they are supported by their favorite organization, they will be assured that the organization will support them in facing managerial conflicts and stressful situations. As a consequence, they like to assume higher value and respect for the organization and contribute to the organization's goals and objectives.

The results showed that perceived organizational support plays a mediating role in the relationship between SOC and job performance. To explain this finding, it can be said that the SOC among nurses leads to higher physical health for them (Masanotti et al., 2020). In other words, a higher sense of coherence among employees leads to increased organizational support from the supervisors, and in turn, the improved job performance of employees. When people perceive an environmental stimulus, the cognitive representation of that stimulus is created in their minds where the controllability of the stimulus is evaluated. Ultimately, the motivations and incentives of the people to deal with that stimulus determine its value and significance (Nasiri Valikbani 2014).

The steps followed in an individual's mind for evaluating a situation are a part of the sense of coherence. Employees with a stronger SOC have higher levels of adaptability and flexibility in their occupations and their workplace, which results in improved job performance. The attitude of these employees towards the situation, themselves, and their capabilities, as well as the value of their activities, make them decisive individuals. While employees with a weaker SOC understand their surrounding environment in a way that creates lots of problems for them. They believe life events to be uncontrollable and they don't have the necessary resources to deal with the demands of such events. For this very reason, they consider life to be valueless and meaningless (Masanotti et al., 2020). In other words, they overestimate the stressful situation or stimulus and underestimate their abilities, causing them to be overwhelmed by the complications of the workplace stress, which not 
only damages their health but also reduces the perceived organizational support, leading to reduced job performance (Bai 2017). Thus, perceived organizational support could properly play a mediating role between SOC and job performance.

Perceived organizational support plays a mediating role between professional ethics and job performance. To explain this finding, it can be said that if the employees have a higher commitment to the principles and criteria of professional ethics, they will have a higher perceived organizational support (Niazazari et al., 2014). Moreover, professional ethics improve and boost the personal accountability of the nurses in the hospital. The presence of professional ethics in nurses has increased the perceived organizational support from supervisors and superiors, improving the job performance and work efficiency of the nurses (Skela-Savic \& Kiger 2015). Therefore, if nurses are hardworking, committed to their occupational responsibilities, accountable to patients and their companions and responsible, and if they pay more attention to the internal incentives for their job and have a collective spirit with their high popularity, they can receive higher levels of organizational support from coworkers and superiors. These conditions improve work conditions and job performance while minimizing the stress caused by work pressure and their work shifts (Hadian Jazi, Peyrovi \& Zareian 2019).

The results of the current study showed that the sense of cohesion had a positive effect on perceived organizational support. Also, professional ethics had a positive effect on job performance and perceived organizational support. Finally, perceived organizational support had a positive effect on job performance. Therefore, perceived organizational support could properly play a mediating role in the relationship between professional ethics and job performance. According to our results, the proposed model provides a good fit, that is an important step towards identifying and understanding factors affecting job performance of nurses. This model can be considered as a good model for devising and designing programs for preventing tensions experienced by nurses, and it can be useful for increasing their job performance.

Based on the results of this study, by improving the underlying context for professional ethics and organizational support in an organization, the trust and job performance of employees can be promoted. In this way, by making rational and informed decisions, the long-term interests of the organization can be guaranteed. Since the statistical population of the current study only included nurses working in Ahvaz City, caution must be exercised when generalizing the results of the study to other populations. It is recommended that more studies be carried out on other samples to safely generalize the results.

\section{Ethical Considerations}

\section{Compliance with ethical guidelines}

The participants willingly completed the questionnaires and signed written informed consent. The study was approved by the Ethics Committee of Islamic Azad University, Ahvaz Branch (IR.IAU.AHVAZ.REC.1398.020).

\section{Funding}

This article was extracted from a part of the $\mathrm{PhD}$. dissertation of Narges Rasouli in the Department of Psychology, Ahvaz Branch, Islamic Azad University, Ahvaz, Iran.

\section{Authors' contributions}

Conceptualization, writing the original draft, reviewing and editing the manuscript: Narges Rasouli, Alireza Heidari; Methodology: Narges Rasouli, Alireza Heidari, Farah Naderi; Investigation: Narges Rasouli, Alireza Heidari, Fatemeh Sadat Marashian; Supervision: Alireza Heidari, Farah Naderi, Fatemeh Sadat Marashian.

\section{Conflict of interest}

The authors declared no conflicts of interest.

\section{Acknowledgments}

We would like to thank all participants, as well as all nurses and employees of Golestan Hospital of Ahvaz City for their kind support.

\section{References}

Akbari, M., Ghasemi Shams, M., \& Pour Mohammasali Chaijani, S., 2018. [Relationship between professional ethics and job conflicts with the mediating role of organizational citizenship behavior (Persian)]. The Journal of Ethics in Science and Technology, 12(4), pp. 108-19. http:/ / ethicsjournal.ir/article-1-885-en. html

Ando, M., \& Kawano, M., 2018. Relationships among moral distress, sense of coherence, and job satisfaction. Nursing Ethics, 25(5), pp. 571-9. [DOI:10.1177/0969733016660882] [PMID]

Antonovsky, A., 1987. Unraveling the mystery of health. How people manage stress and stay well. San Francisco: Jossey-Bass Publishers. 
Bai, N., 2017. [Studying relationship between perceived organizational support and job performance of Golestan province physical education teachers (Persian)]. Journal of Human Resource Management in Sport, 4(2), pp. 189-99. https:/ / www.sid. ir/en/journal/ViewPaper.aspx?id=605416

Banks, S., 2015. Everyday ethics in professional life: Social work as ethics work. Ethics and Social Welfare, 10(1), pp. 35-52. [DOI: 10.1080/17496535.2015.1126623]

Cadozier, V., 2002. The moral profession: A study of moral development and professional ethics of faculty. University of Texas Libraries. Available from: https://repositories.lib. utexas.edu/handle/2152/10560.

Caesens, G., et al., 2016. The relationship between perceived organizational support and proactive behaviour directed towards the organization. European Journal of Work and Organizational Psychology, 25(3), pp. 398-411. [DOI:10.1080/135943 2X.2015.1092960]

Chye Koh, H. C., \& Boo, E. H. Y., 2004. Organisational ethics and employee satisfaction and commitment. Management Decision, 42(5), pp. 677-93. [DOI:10.1108/00251740410538514]

Dare Azeez, F., 2019. Role ambiguity and organizational justice as the predictors of unethical behavior among nurses. Journal of Client-Centered Nursing Care, 5(2), pp. 81-6. [DOI:10.32598/ JCCNC.5.2.81]

Debska, G., Pasek, M., \& Wilczek-Rużyczka, E., 2017. Sense of coherence vs. mental load in nurses working at a chemotherapy ward. Central European Journal of Public Health, 25(1), pp. 35-40. [DOI:10.21101/cejph.a4305] [PMID]

DeConinck, J., \& Deconinck, M. B., 2017. The relationship between servant leadership, perceived organizational support, performance, and turnover among business to business salespeople. Global Journal of Management and Marketing, 5(10), pp. 57-71. [DOI:10.14738/abr.510.3730]

Ehteshamzadeh, P., Sabri Nazarzadeh, R. \& Memarbashi Aval, M., 2014. [The relationship between sense of coherence and job performance with intermediation strategies of coping with stress and mental health (Persian)]. Journal Management System, 4(13), pp. 85-97. http://jpmm.miau.ac.ir/article_342.html

Eisenberger, R., et al., 2001. Reciprocation of perceived organizational support. Journal of Applied Psychology, 86(1), pp. 42-51. [DOI:10.1037/0021-9010.86.1.42] [PMID]

Ekramifar, F., et al., 2018. The effect of spiritual training on the moral sensitivity of nursing students. Journal of Client-Centered Nursing Care, 4(4), pp. 213-22. [DOI:10.32598/jccnc.4.4.213]

Fagbenro, D. A. 2019. Role Ambiguity and Organizational Justice as the Predictors of Unethical Behavior Among Nurses. Journal of Client-Centered Nursing Care, 5(2), 81-86. [DOI:10.32598/ jccnc.5.2.81]

Farahaninia, M., et al., 2019. relationship between nurses' social health and quality of life. Journal of Client-Centered Nursing Care, 5(2), pp. 131-40. [DOI:10.32598/JCCNC.5.2.131]

Flensborg-Madsen, T., Ventegodt, S., \& Merrick, J., 2006. Sense of coherence and physical health. A cross-sectional study using a new scale (SOC II). The Scientific World Journal, 6, pp. 2200-11. [DOI:10.1100/tsw.2006.350] [PMID] [PMCID]

Ghanbari, S., Soltaninejad, H., \& Badafara, M., 2018. [Investigating the impact of perceived organizational support on employee job performance (Study; Power Distribution Company) (Persian)]. Quality and Productivity, 13(13), pp. 144-9. http://nqpc.ir/article-I-r \A-fa.html

Guo, J., et al., 2016. Structural empowerment, job stress and burnout of nurses in China. Applied Nursing Research, 31, pp. 41-5. [DOI:10.1016/j.apnr.2015.12.007] [PMID]

Hadian Jazi, Z., Peyrovi, H., \& Zareian, A., 2019. Nurse's social responsibility: A hybrid concept analysis in Iran. Medical Journal of the Islamic Republic of Iran, 33, p. 44. [DOI:10.34171/ mjiri.33.44] [PMID] [PMCID]

Kangasniemi, M., Pakkanen, P., \& Korhonen, A., 2015. Professional ethics in nursing: An integrative review. Journal of Advanced Nursing, 71(8), pp. 1744-57. [DOI:10.1111/jan.12619] [PMID]

Kim, K. Y., Eisenberger, R., \& Baik, K., 2016. Perceived organizational support and affective organizational commitment: Moderating influence of perceived organizational competence. Journal of Organizational Behavior, 37(4), pp. 558-83. [DOI:10.1002/job.2081]

Lamm, E., Tosti-Kharas, J., \& King, C. E., 2015. Empowering employee sustainability: Perceived organizational support toward the environment. Journal of Business Ethics, 128, pp. 207-20. [DOI:10.1007/s10551-014-2093-z]

Lazaroiu, G., 2015. Employee motivation and job performance. Linguistic and Philosophical Investigations, 14(1), pp. 97-102. https://www.researchgate.net/publication/282986447_Employee_motivation_and_job_performance

Masa'deh, R., Obeidat, B. Y., \& Tarhini, A., 2016. A Jordanian empirical study of the associations among transformational leadership, transactional leadership, knowledge sharing, job performance, and firm performance: A structural equation modelling approach. Journal of Management Development, 35(5) pp. 681-705. [DOI:10.1108/JMD-09-2015-0134]

Masanotti, G. M., et al., 2020. Sense of coherence in nurses: A systematic review. International Journal of Environmental Research and Public Health, 17(6), p. 1861. [DOI:10.3390/ijerph17061861] [PMID] [PMCID]

Memarbashi Aval, M., Sabri Nazarzadeh, R., \& Abdolkhodaei, M. S., 2012. [The relationship between sense of coherence and self-esteem with job performance (Persian)]. Career and Organizational Counseling, 4(12), pp. 66-78. https://www.sid.ir/en/ Journal/ViewPaper.aspx?ID=280884

Moradi, S., Ghodrati Mirkohi, M., \& Hayati, M., 2019. [The effectiveness of the life review program on sense of loneliness, social adjustment, coherence and integration in the elderly (Persian)]. Aging Psychology, 5(3), pp. 179-99. [DOI:10.22126/ JAP.2019.1225]

Nasiri Valik Bani, F., 2014. [The relationship between perceived organizational protection of urban management with social responsibility and municipal employees' job performance of Hamadan (Persian)]. Journal of Urban Economics and Management, 2(8), pp. 97-108. http://iueam.ir/article-1-88-en.html

Niazazari, K., et al., 2014. [Relationship between professional ethics and job commitment (Persian)]. Iran Journal of Nursing, 27(87), pp. 34-42. [DOI:10.29252/ijn.27.87.34]

Oreizi samani, H. R., Dibaji, S. M., \& Sadeghi, M., 2012. [Investigation the relationship of work-family conflict with perceived organizational support, job stress and self-mastery in expa- 
triate workers (Persian)]. Research in Clinical Psychology and Counseling, 1(2), pp. 151-70. https:/ / www.sid.ir/en/Journal/ ViewPaper.aspx?ID=245087

Orgambidez-Ramos, A., Moura, D., \& de Almeida, H., 2017. [Role stress and psychological empowerment as antecedents of job satisfaction (Español)]. Revista de Psicología. 35(1), 257-79. [DOI:10.18800/psico.201701.009]

Özden, D., et al., 2019. The effect of nurses' ethical leadership and ethical climate perceptions on job satisfaction. Nursing Ethics, 26(4), pp. 1211-25. [DOI:10.1177/0969733017736924] [PMID]

Paterson, T. T., \& Husband, T. M., 1970. Decision-making responsibility: Yardstick for job evaluation. Compensation Review, 2(2), 21-31. [DOI:10.1177/088636877000200204]

Qorbanpoor Lafmejani, A., Yaghouti, M., \& Rezaei, S., 2019. [The mediating role of social support in the relationship between mental hardiness and the sense of coherence with quality of life among staff at hospitals in Quchan (Persian)]. Social Psychology Research, 9(34), pp. 119-39. https://www.sid.ir/fa/ Journal $/$ ViewPaper.aspx?id=508130

Sagheb Esmaeelpour, M., et al., 2019. [The relationship of work ethics with job performance of the administrative and medical staff of the university of social welfare and rehabilitation sciences and its affiliated centers in 2017 (Persian)]. Archives of Rehabilitation, 20(1), pp. 52-63. [DOI:10.32598/rj.20.1.52]

Shaghozaei, F., Marziyeh, A., \& Nastezaei, N., 2018. [The relationship of professional ethics with social competence and job performance case study: Staff of Zahedan technical and vocational training organization (Persian)]. Management Researches, 11(39), pp. 113-34. https://www.sid.ir/en/journal/ViewPaper.aspx?id=648606

Skela-Savic, B., \& Kiger, A., 2015. Self-assessment of clinical nurse mentors as dimensions of professional development and the capability of developing ethical values at nursing students: A correlational research study. Nurse Education Today, 35(10), pp. 1044-51. [DOI:10.1016/j.nedt.2015.04.003] [PMID]

de Souza, J. D., Pessoa Júnior, J. M. \& de Miranda, F. A. N., 2017. Stress in an emergency room and the challenges for Brazilian and Portuguese nurses. Revista de Enfermagem Referência IV Série, 12, pp. 107-16. [DOI:10.12707/RIV16064]

Taheri Attar, G., Pourahmadi, M., \& Herati, M., 2019. [An Analysis of the effect of professional ethics on organizational performance and trust through the mediating role of ethical climate (Persian)]. Management, 11(1), pp. 27-56. https://tmj. um.ac.ir/article/view/69484

Tims, M., Bakker, A. B., \& Derks, D., 2013. The impact of job crafting on job demands, job resources, and well-being. Journal of Occupational Health Psychology, 18(2), pp. 230-40. [DOI:10.1037/a0032141] [PMID]

Vainio, M. M., \& Daukantaitè, D., 2016. Grit and different aspects of well-being: Direct and indirect relationships via sense of coherence and authenticity. Journal of Happiness Studies, 17(5), pp. 2119-47. [DOI:10.1007/s10902-015-9688-7]

Vasegh Rahimparvar, S. F., et al., 2018. Effects of professional labor support education to Iranian midwifery students on mothers' satisfaction. Journal of Client-Centered Nursing Care, 4(3), pp. 123-30. [DOI:10.32598/jccnc.4.3.123]
Viswesvaran, C., \& Ones, D. S., 2017. Job performance: Assessment issues in personnel selection. The Blackwell Handbook of Personnel Selection, pp. 354-75. [DOI:10.1002/9781405164221.ch16]

Winger, J. G., Adams, R. N., \& Mosher, C. E., 2016. Relations of meaning in life and sense of coherence to distress in cancer patients: A meta-analysis. Psychooncology, 25(1), pp. 2-10. [DOI:10.1002/pon.3798] [PMID] [PMCID]

Zaki, M. A., 2006. [Assessing and measuring organizational support (Persian)]. Journal of the Faculty of Administrative Sciences and Economics, University of Isfahan, 18(3), pp. 103-23. https:/ / www.sid.ir/fa/journal/ViewPaper.aspx?ID=213776

Zheng, J., \& Wu, G., 2018. Work-family conflict, perceived organizational support and professional commitment: A mediation mechanism for Chinese project professionals. International Journal of Environmental Research and Public Health, 15(2), p. 344. [DOI:10.3390/ijerph15020344] [PMID] [PMCID]

Zhong, L., Wayne, S. J., \& Liden, R. C., 2016. Job engagement, perceived organizational support, high-performance human resource practices, and cultural value orientations: A crosslevel investigation. Journal of Organizational Behavior, 37(6), pp. 823-44. [DOI:10.1002/job.2076] 
This Page Intentionally Left Blank 